\title{
Then and now: evolving community in the context of a retirement village
}

\author{
Miriam Bernard ${ }^{1}$, Jennifer Liddle ${ }^{1}$, Bernadette Bartlam ${ }^{1}$, Thomas Scharf ${ }^{2}$ and Julius Sim ${ }^{1}$ \\ ${ }^{1}$ Centre for Social Gerontology, Keele University, Keele, UK. \\ ${ }^{2}$ Irish Centre for Social Gerontology, National University of Ireland, Galway, Ireland.
}

\begin{abstract}
There is currently much debate in the United Kingdom policy and practice literature about how best to respond to the care and accommodation needs of people as they retire and grow older. Against a policy background which espouses the benefits of 'lifetime homes and lifetime neighbourhoods', the growth of purpose-built segregated retirement villages looks somewhat contradictory and is set to transform the housing scene. Whilst there has been considerable research into these environments in countries like the United States of America and Australia, we know comparatively little about what it is like to live in British retirement communities, how they evolve over time and whether they enhance people's lifestyle aspirations and quality of life. This paper examines these issues through the lens of 'community' and in the context of Denham Garden Village: a purpose-built retirement village in Buckinghamshire. Drawing on a range of qualitative data (from individual and group interviews, diaries and directives), we focus on how 'community' was conceptualised, experienced and understood both 'then' (in the early days of the village) and 'now' (subsequent to its redevelopment). The findings enable us to examine the extent to which 'community' evolves over time and raise important questions about how socially cohesive, or not, such retirement villages are.
\end{abstract}

KEY WORDS - community, retirement village, community of interest, community identity, community of place.

\section{INTRODUCTION}

In the United Kingdom (UK), as elsewhere, knowledge and research about older people has flourished over recent years and many of the issues presented by the rapid ageing of our populations are well known and well rehearsed. However, notwithstanding the fact that older people are as demographically, socially and economically diverse as younger people (Bernard and Scharf 2007), it is evident that policy and practice developments often treat them as if their needs and requirements are homogeneous. One key area, which forms the focus of this article, concerns the kinds of living environments that might best suit older people. Under the New Labour government (1997-2010), purpose-built developments - and especially retirement villages - were set to transform the UK housing scene (Department for Communities and Local Government 2008; Evans 2009 a). Whilst it is too early to see clearly what might happen to housing and accommodation for older people under the Conservative-Liberal Democrat coalition government, it is still evident that we know comparatively little about what it is actually like to live in purpose-built retirement communities. Nor do we know how they evolve over time; whether they enhance people's lifestyle aspirations and quality of life; and if they provide acceptable solutions to older people's changing needs for accommodation and care (Bernard et al. 2007).

This article addresses the above issues by exploring how one 'community' has evolved and 
changed over time. Denham Garden Village (DGV) in Buckinghamshire, England is a rare example of a retirement community that has existed since the 1950s. Opened in 1958, DGV was originally owned and managed by the Licensed Victuallers National Homes (LVNH) organisation. In 2001, financial pressures, combined with essential maintenance and modernisation costs, led to Anchor Trust (England's largest provider of care and accommodation for older people) taking over the village and other LVNH sites. Since then, DGV has been redeveloped and now provides a total of 326 properties for people aged 55 and over.

Consequently, our article first examines the historical, research and policy background to this and similar developments, looking in particular at conceptualisations of 'retirement' and 'community'. It then details a longitudinal study of DGV under way since 2006, explaining how the study is being carried out before presenting some of our findings about how 'community' was conceptualised, experienced and understood both 'then' (in the early days of the village) and 'now' (subsequent to its re- development). In focusing our attention on 'community', our work is set within, and draws on, a substantive body of work from disciplines such as geography, sociology and psychology which have long emphasised the importance of 'place' and 'space' in contributing to understandings of community and identity (Canter 1977; Crow and Allan 1994; Holloway and Hubbard 2001; Phillipson and Allan 2008; Rose 1995; Tuan 1977). In this instance, our concern is to identify features of life in a retirement village which facilitate or impede the evolution of a sense of community and we therefore frame our discussions around three key dimensions: 'community of place', 'community of interest' and 'community identity'. In so doing, we examine how 'community' evolves over time and raise further questions about how socially cohesive, or not, such purpose-built retirement villages are.

\section{Retirement communities in ageing societies}

Retirement communities have existed in Britain since Roman times, when they were built to accommodate military officers who had retired from active duty with distinguished service records (Karn 1977). Across Europe too, retirement schemes with religious affiliations have been a long- standing feature of provision for older people since medieval times. However, the major growth in such developments occurred initially during the 20th century when the concept spread from Europe to North America (Burgess 1961). Evans (2009 a) cites work by Webster (2002) which shows that purpose-built retirement communities now account for approximately 11 per cent of all new housing in the USA. It is estimated that about 12 per cent of the older population live in these developments (Webster 2002) and there are now over 2,000 retirement villages with some, like 'Sun City' in Arizona and 'The Villages' in Florida, housing tens of thousands of people.

Comparable figures for the UK are hard to come by, not least because there are no nationally collated statistics specifically related to this trend. However, the Elderly Accommodation Counsel (EAC; www.eac.org.uk) manages a 'Housing Options' database of UK sheltered and retirement housing for older people which, at the time of writing, includes information on 25,700 schemes for rent or purchase (http://www.eac.org.uk/ shop/countyguides-sheltered-retirement-housing.aspx). In addition, their current online 'Directory of retirement villages and communities in the UK' (EAC 2009), lists 77 schemes described by their developers and managers as 'retirement villages' (Evans 2009 a). However, as in other countries (Jones et al. 2009), there is still no universally agreed definition in the UK of what constitutes a retirement village.

'Retirement', 'village' and 'community' are all contested and debated terms. 'Retirement' sits uneasily with the ethos that many of the developers of these villages are trying to promote. Far from encouraging people to retire they are marketed, particularly in the United States of America, as environments in which people are encouraged to participate, and to become or stay active (Katz and McHugh 2010; McHugh 2000). The publicity material for DGV is a 
case in point, describing it as a community offering 'exciting leisure activities' with 'as much or as little social activity as you want' (DGV 2009). Moreover, previous research suggests that using the word 'retirement' in the phrases 'retirement village' or 'retirement community', may mean that residents and their families have expectations that people will be looked after in ways akin to being in a residential or nursing home, rather than living in an environment designed to encourage and support them to lead independent lives (Bernard et al. 2004). We also know from early studies of these environments in North America that retirement - in the sense of formal retirement from paid work - may not in fact be the prime motivation for moving to a retirement village (Marans, Hunt and Vakalo 1984). In fact, the word 'retirement' has been dropped in some of the newer developments in the UK.

If 'retirement' is a difficult term in this context, then the words 'community' and 'village' are no less fraught with problems. Geographers will be familiar with attempts to articulate different morphological categories of villages based on increasingly complex measures of density, land use, context and settlement type (Bibby and Shepherd 2004). However, a quick glance at aerial images of existing retirement villages reveals that hardly any of them fit either the more traditional or contemporary definitions or perceptions of what a 'village' is (Bernard et al. 2004; Croucher, Pleace and Bevan 2003; Croucher et al. 2007; Evans and Means 2007). Morphologically and locationally, existing retirement villages are all very different from one another; they vary from rural to suburban to urban settings, and some are in fact just a single building (Bernard et al. 2004). Moreover, the word 'village' is also a socially constructed term: one used informally by residents themselves to invoke idealised notions of village life (Evans 2009 a, 2009 b) but also as a marketing device by developers in their efforts to attract buyers to these age-segregated settings (Simpson 2007).

The word 'community' also presents difficulties not least because it is often used interchangeably with 'village'. However, the term 'retirement community' is also used to encompass a broader range of housing options, including privately owned apartments, extra-care housing, nursing care homes, specialist dementia care units and continuing care retirement communities. Moreover, retirement villages like DGV are often marketed as communities of like-minded people, and concepts such as 'community cohesion', 'community engagement' and 'sustainable communities' were central to many of the policy initiatives espoused by the previous Labour administration in the UK (www.communities. gov.uk/communities). Even with a change of government, it still appears that community 'is firmly back at the top of the agenda' (Evans 2009a: 7).

\section{Understandings of 'community'}

If we are to focus on retirement villages as particular types of community, it is helpful to try to delineate the various dimensions of community with which we might be concerned. From a theoretical perspective, and for the sake of clarity, we frame our discussions around the three key dimensions of community identified in a recent review of the literature by Evans (2009 a): 'community of place', 'community of interest' and 'community identity'. 'Place', in the sense of locality, has long been key to under- standing people's relationships with where they live and with each other (Easthope 2004; Tuan 1977, 2001) and older people in particular are very likely to have spent considerable periods of their lives in one place; one neighbourhood, one home (Peace, Holland and Kellaher 2006; Peace et al. 2007; Rowles 1978; Smith 2009). Often, therefore, their lives are bounded by the physical environment and lived out within a given set of places and spaces (Burholt 2006).

Traditionally, it was also assumed that those who live in the same geographical area somehow develop a shared identity and, to a lesser extent, shared interests (Evans 2009 a). However, alternative, but not necessarily mutually exclusive perspectives, suggest that place is less important to a sense of belonging and identity formation than people's individual biographies and what has been termed 'elective belonging' (Savage 2008; Savage, Bagnall 
and Longhurst 2005). Yet, it is far from clear how a retirement village, as a geographical entity, operates in these respects. Although there has been important research in North American retirement communities exploring the interplay between the physical context and the experience of ageing (Laws 1995, 1997; Osgood 1982; Streib 2002), there is little comparative work to date in a UK context. We do not know, for example, the extent to which an environment like DGV constrains or facilitates the social worlds and social relationships of long-time residents. Nor do we know how identities and interests might have evolved over time, or what incomers think and feel about this new place in which they find themselves in later life. Moreover, major social changes such as globalisation, coupled with technological advancements, mean that it is also now possible to reside in one place and yet be embedded in a complex web of social relationships and social interests outwith that community (Eade 1997; Massey 2005).

The second key dimension of community is therefore that of 'interest'. 'Communities of interest' have traditionally overlapped with 'communities of place', as was the case with the first religiously affiliated European retirement schemes. Communities of interest may also be based on shared heritage and include 'occupational communities' developed around particular workplaces or jobs. Crow and Allan (1994) emphasise the tight bonds, shared leisure interests and shared meanings that studies of mining communities have highlighted and it is quite possible that, as licensed victuallers, the original residents of DGV will exhibit similar understandings of community.

The third key dimension of community is that of 'identity'. It has been observed that where people identify with - or are attached to - a given place, or indeed a given culture, a shared sense of identity can evolve. Feelings of belonging and attachment are, in turn, often expressed through collective action or community spirit (Crow and Allan 1994). As Sarason (1974: 157) asserted, this psychological sense of community 'is one of the major bases for self-definition', whilst more recent literature on identity and place also provides evidence of a strong link between an older person's environment and his or her sense of self (Andrews and Phillips 2005; Peace, Holland and Kellaher 2005, 2006; Rowles and Watkins 2003; Scharf, Phillipson and Smith 2007; Smith 2009).

One of the defining characteristics of this dimension of community is the nature of interactions between people which lead, in McMillan and Chavis's (1986: 9) words, to a shared 'sense of community'. As communities begin to form, and retirement communities are probably no exception, people look for similarity in others, because 'if one can find people with similar ways of looking, feeling, thinking and being, then it is assumed that one has found a place where one can safely be oneself' (McMillan 1996: 321). Perceived similarity to others contributes to group interaction and cohesion, as does a shared history. This shared history in turn 'becomes the community's story' (McMillan 1996: 322) whose values and traditions may well 'outlive community members and remain a part of the spirit of the community' (McMillan 1996: 323). McMillan and Chavis (1986) conclude that a welldefined and empirically validated understanding of how community is experienced, as opposed to its other features such as its structure or setting, might in fact help planners and developers of all kinds of programmes and services.

Although 'sense of community' has long been examined in North American planned towns and retirement communities (Blakely and Snyder 1999; Jacobs 1983; Osgood 1982; Plas and Lewis 1996; Ross 1977; Streib and Metsch 2002; Sugihara and Evans 2000; van den Hoonaard 2002), empirical validation in the context of UK purpose-built retirement villages is limited. Between 1999 and 2006, there were only two published papers in the UK reporting primary research and evaluation studies of retirement communities (Bernard et al. 2004; Croucher, Pleace and Bevan 2003). However, these studies indicate that such environments may indeed provide residents with a place in which many of them can maintain a relatively stable social identity and where neighbourliness and volunteering are valued ways of expressing commitment to a shared community (Bernard et al. 2004; Biggs et al. 2000; 
Croucher, Pleace and Bevan 2003).

More recently, Evans (2009a: 129) has linked conceptualisations of 'community' and 'sense of community' together into a theory of 'community in place'. He proposes that retirement communities, as physical places and spaces, provide a built environment and a secure setting within which the social interactions that form the basis for a sense of community can be developed and sustained. Thus, the environment has social and psychological, as well as physical, dimensions, within which individuals interact and in which they invest meanings (Peace, Holland and Kellaher 2006; Peace et al. 2007). It may be possible then, in the face of a wider society which persists in devaluing and marginalising old age and old people (Nelson 2005), that purpose-built retirement villages could provide a direct challenge to contemporary ageing identities by bolstering people's sense of who they are as they age and helping to create a secure and convincing narrative for identity in later life (Biggs et al. 2000; Laws 1995). It was against this background that our study of DGV sought to explore how people who live and work there experienced it as an evolving community.

\section{THE STUDY OF DENHAM GARDEN VILLAGE}

DGV was the site for a four-year long mixed-method project with the acronym LARC (Longitudinal study of Ageing in a Retirement Community). LARC began in June 2006 and included biannual surveys of the resident population alongside qualitative methods involving ethnography, diary-keeping by residents, individual and group interviews, annual community conferences, regular waves of directed writing by residents, and photographic/audio-visual work. ${ }^{1}$ It was framed by a series of research questions that, in addition to reflecting Anchor Trust's concerns about the development of DGV, were designed to illuminate a number of more fundamental issues around what it might be like to age in such purpose- built environments. In this article, we focus on residents' attitudes to living in such a mixedtenure, purpose-built, age-segregated community and ask :

- What was DGV like as a community in the early days ?

- How has DGV evolved as a community since the redevelopment began

- in 2001 ?

- How do today's residents perceive and experience the village as a community? 
TABLE 1: Socio-demographic profiles of residents

\begin{tabular}{|c|c|c|c|}
\hline & $\begin{array}{l}\text { Number of } \\
\text { interviews }\end{array}$ & $\begin{array}{c}\text { Number of } \\
\text { diaries }\end{array}$ & $\begin{array}{c}\text { Number of } \\
\text { directives }\end{array}$ \\
\hline \multicolumn{4}{|l|}{ Gender: } \\
\hline Male & 2 & 3 & 10 \\
\hline Female & 3 & 8 & 31 \\
\hline \multicolumn{4}{|l|}{ Age (years): } \\
\hline $55-64$ & 0 & 1 & 5 \\
\hline $65-74$ & 0 & 4 & 12 \\
\hline $75-84$ & 2 & 5 & 17 \\
\hline $85-94$ & 3 & 1 & 7 \\
\hline \multicolumn{4}{|l|}{ Length of residence (years): } \\
\hline$<1$ & 0 & 5 & 17 \\
\hline $1-4$ & 0 & 3 & 18 \\
\hline $5-9$ & 0 & 1 & 1 \\
\hline $10-14$ & 5 & 2 & 5 \\
\hline \multicolumn{4}{|l|}{ Household composition: ${ }^{1}$} \\
\hline Living alone & 3 & 5 & 18 \\
\hline Living with one other person & 2 & 6 & 19 \\
\hline Living with more than one & 0 & 0 & 1 \\
\hline other person & & & \\
\hline Unknown & 0 & 0 & 3 \\
\hline \multicolumn{4}{|l|}{ Ethnicity: $^{2}$} \\
\hline English & 4 & 8 & 25 \\
\hline Other British & 1 & 0 & 6 \\
\hline Irish & 0 & 1 & 1 \\
\hline Other White & 0 & 1 & 1 \\
\hline Indian & 0 & 0 & 1 \\
\hline Unknown & 0 & 1 & 7 \\
\hline \multicolumn{4}{|l|}{ Tenure : } \\
\hline Rental & 5 & 4 & 14 \\
\hline Leasehold & 0 & 7 & 27 \\
\hline Number of responses & $4^{3}$ & 11 & 50 \\
\hline Sample size & 5 & 11 & 41 \\
\hline
\end{tabular}

Notes: ${ }^{1}$ Information is only available for residents who took part in either survey or who had partners who took part in either survey. ${ }^{2}$ Information is only available for residents who took part in either survey. ${ }^{3}$ One interview was completed with a couple.

The findings presented and discussed below draw on data from 52 residents and from 16 individuals associated with a variety of organisations involved in the (re)development of DGV. In particular, we draw on diaries and directives written by residents and on two sets of semi-structured interviews. The mixed-method nature of this study meant that residents could choose to take part in one or more elements. For example, one resident might have completed a diary and a number of directives; another may have participated just in an interview. Socio-demographic details of the 52 residents are derived from the village-wide surveys conducted in 2007 and 2009 (see Table 1). As Table 1 shows, 11 residents completed diaries in which they recorded their experiences of life in the village writing, for example, about the sorts of things they did socially and for recreation; the ways in which they did (or did not) join in life at DGV; and the sorts of relationships they had with neighbours and people working in the village. LARC directives are invitations to residents to write on particular topics and were issued twice yearly (see www.massobs.org.uk). In this paper, we draw on 50 responses (from 41 residents, see Table 1 ) to the first three directives: 
one on 'First impressions of Denham Garden Village' (22 responses); one on 'Staying active' (14 responses), and one on 'Community life at Denham Garden Village' (14 responses).

The first set of semi-structured interviews was undertaken with 16 individuals who were involved in helping to formulate a vision for what was being promoted by the developers (Anchor Trust) as a flagship retirement community. Eleven of these interviews were with Anchor/DGV senior personnel (past and present) and five were with individuals from the LVNH organisation and from the architectural practice, estate agents and marketing agencies working on the redevelopment. ${ }^{2}$ Their involvement had been at either an operational or strategic level and the inter- views explored respondents' differing perspectives on how DGV might continue to evolve as a community. The second set of interviews focused on the experiences of five of the licensed victuallers who had lived at DGV for a considerable time (see Table 1). The interviews considered how the original village impacted on their sense of identity, and how the redevelopment was affecting them both individually and as a community.

Following Ritchie, Spencer and O'Connor's (2003) analytical process, at least two members of the research team (and sometimes three) have independently reviewed the qualitative data and agreed on a series of themes and sub-themes relating to 'community' in its broadest sense. Using what Mason (2006: 8) describes as 'corroborative logic', where 'different forms of data and method are used to corroborate what they are measuring', we draw out a series of themes from the myriad perceptions, views and experiences captured in the data. These themes not only reflect the literature on community reviewed above, but also call attention to the overriding comparisons between 'then' and 'now' that participants made in the interviews and in their written accounts. The findings are therefore presented around three main themes: DGV as a 'community of place': then and now; DGV as a 'community of interest': then and now; and DGV and 'community identity': then and now. The 16 individuals who participated in the first set of semi-structured interviews are each given a unique identifier (e.g. Key 1, Key 2 etc.) whilst all residents, whether they were interviewees, diary-keepers or respondents to the directives, are given pseudonyms.

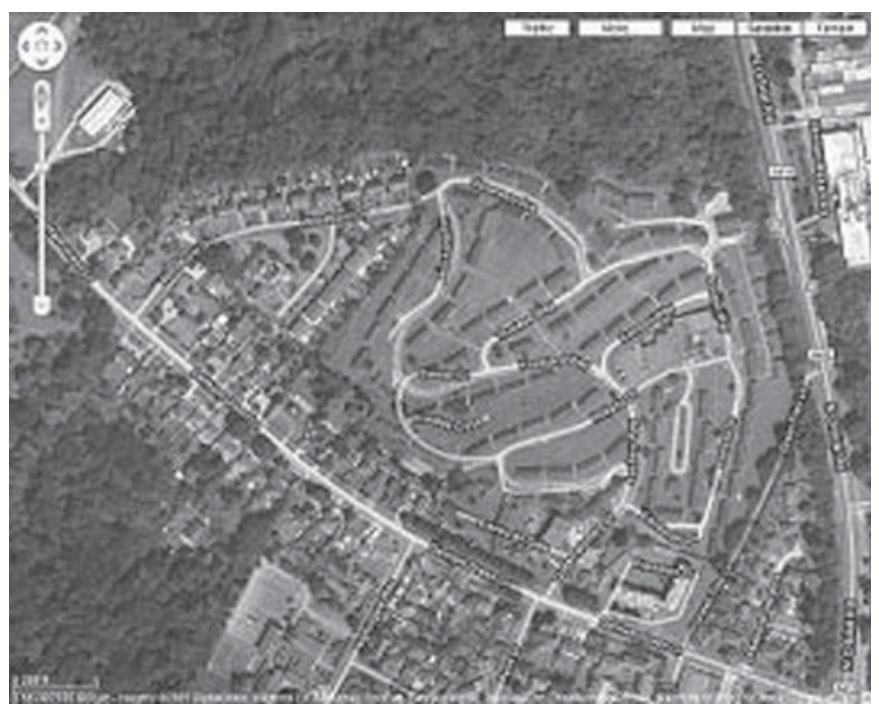

FIGURE 1: Denham Garden Village before redevelopment. 


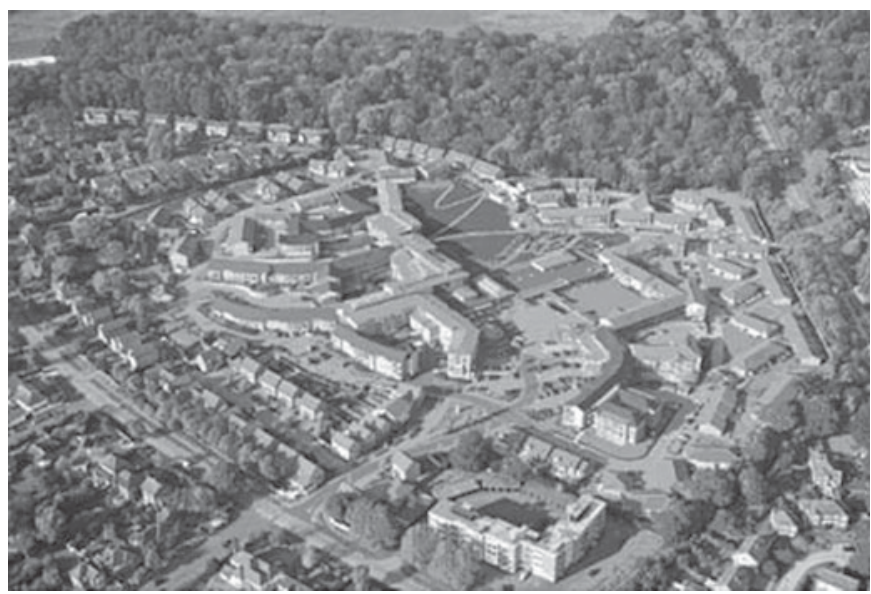

FIGURE 2: Denham Garden Village after redevelopment.

\section{DGV as a 'community of place': then and now}

Located to the north-west of London on the edge of the Chiltern Hills, DGV was built to provide accommodation for retired licensees who were facing economic hardship and/or experiencing ill health. As can be seen from the aerial photographs in Figures 1 and 2, it is bounded on the north by an area of woodland (Nightingale Wood); to the east by the main A412 road; to the south by Denham Green Lane and the village of Denham Green, and to the west (and north-west) by additional woodland and the open space of Denham aerodrome. Less evident from the photographs is the sloping nature of the terrain: dropping in the space of less than half a kilometre from a height of approximately 60 metres at the site's north- western extremity down to 45 metres at the entrance to the village on Denham Green Lane.

The aerial photograph of DGV as it was before the redevelopment began in 2001 (Figure 1) shows that it looked much like a suburban estate with very little in the way of physical barriers or landmarks to distinguish it from the surrounding residential streets and housing. On entering the village from Denham Green Lane, there was a large 100-bed nursing home set back from the road: a key landmark and a key facility. Indeed, the presence of the nursing home was one of the primary reasons for many of the original licensed victuallers moving to DGV, as Nettie Gray observed:

I think the main reason too we thought about coming in here, quite a lot of us, was that nursing home: that when we were really ill we could go there and they would look after us.

The physical layout and the location of buildings like the nursing home were also visual reminders of what people had moved to and what might happen as residents grew older :

To begin with they used to put - when you first entered the estate - you were put right on the top and, as you became more aged, so you'd move down 'til, eventually, you went into the nursing home ... and you went through the nursing home in a circle : round 'til eventually you got to the actual hospital side of the nursing home and that's where you then ended your days. So, it was - if you look at it - a conveyor belt, but it was done so nicely ... and we cared about people, so we put all the younger ones right on the top of that bank and slowly came down. (Key 10)

In the heart of the old village (just to the east of its geographical centre), was another complex of buildings accommodating the village pub called 'The Owl' and the social club, the concert-cum-dance hall, and the village shop and post office (see Figure 1). This was the main hub of community life - and it is this notion of a village centre that has been retained 
even though the site has been completely redeveloped and remodelled.

As Figure 1 also shows, the hilly nature of the site initially dictated how the roads and bungalows were built. The roads followed the contours with very few dead ends or cul-desacs. The 188 one- and two-bedroom (semi-detached) bungalows were ranged in parallel with the roads, had no garages, and were separated from one another by large expanses of shared, communal open space with fences or walls being notable by their absence (Figure 3).

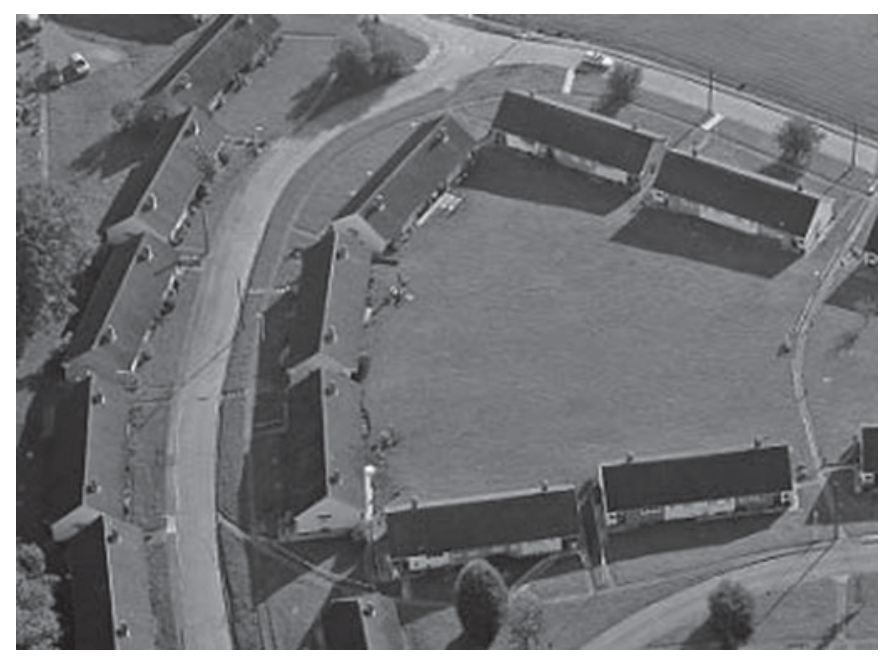

FIGURE 3: Original bungalows.

Today, mixed-tenure accommodation and a variety of housing stock have replaced the old rented bungalows and the nursing home. DGV now comprises a mix of leasehold and rented accommodation, ranging from one- and two-bedroom apartments through to bungalows (some with up to three bedrooms) and detached two- and three-bedroom houses. All are designed to Lifetime Homes standards (British Standards Institute 2007) and many of the individual properties have well-defined and fenced-in gardens. Even where this is not permitted (as with the rented bungalows), residents have tended to delineate their territory with trellising, sheds and other physical markers (Figure 4).

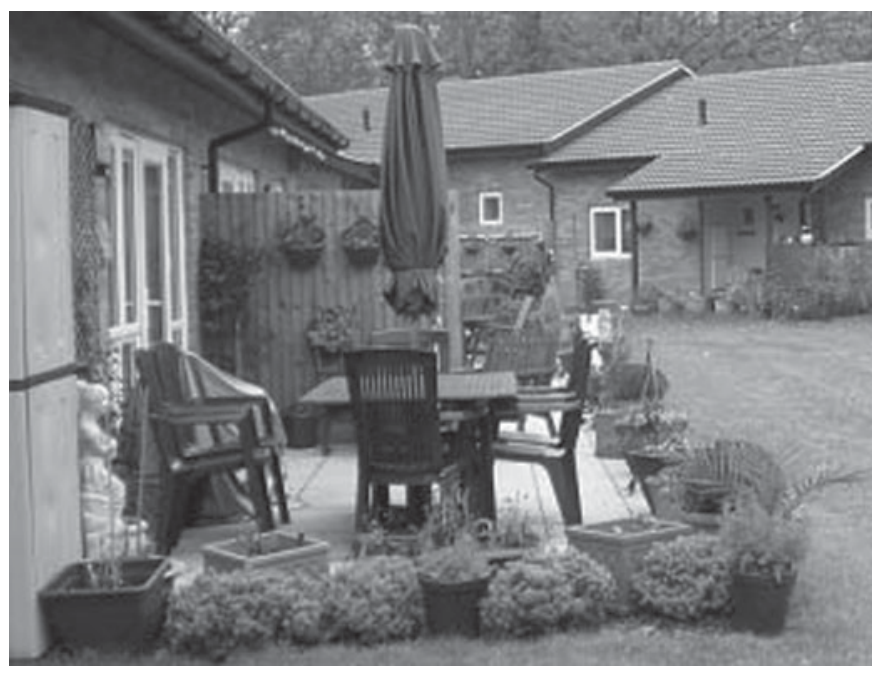

FIGURE 4: New bungalows.

Despite some initial reservations (especially amongst those licensed victuallers moving from bungalows into apartments), many residents, like Lillian Martin, find the new accommodation of better quality and more spacious: 
Well when we first come we thought they were going to be horrible. But once we came up here and seen it when it was finished, we thought what a lot of space, much more space than there was in the bungalow. Much more space. The bedroom, the little bedroom that we had in the bungalow you couldn't even get a single bed in it, could you?

However, whilst the accommodation may be better, there are still issues for some residents about where exactly they are located, either in a given building or on the site more generally. For example, residents living on the edges of the site told us that they found the sloping terrain, and the distances from their properties to the central facilities such as the village hall and the cafe' bar, a drawback to participating in village life. As Figure 2 shows, the site now looks very different indeed from how it was prior to the redevelopment; accommodation is at a much higher density and, although the main arterial roads remain, a number of the buildings cross rather than follow the contours. Accessibility is key and the new village has covered external walkways, suggested routes, regular shelters and no raised pavements. New central facilities include a shop, cafe' bar, GP surgery, library, village hall, winter garden and a health spa (incorporating a gym, swimming pool and hairdresser). The largest of these central buildings also incorporates apartments and is deliberately designed to be visible from all parts of the village so that: 'people anywhere on the site can get to this centre, you know, very easily, in terms of level access, and a degree of cover' (Key 11).

As in the 'old' village, particular facilities and buildings are still important in identifying the village as a community, with the cafe' bar having the potential to be a major focal point. To date, however, it has received mixed reviews, although residents like Dora Atkins recognise that: 'more people using [the] café bar - meeting new friends over a meal or a drink' would enhance community life. In addition, 'having the Doctor on our doorstep' (Rosa Scott) is greatly valued by residents for, as one of the key informants noted: 'it's one of those key building blocks that brings people in and roots it in the community' (Key 11).

\section{DGV as a 'community of interest': then and now}

As noted earlier, 'communities of interest' have traditionally overlapped with 'communities of place', and may have their origins in a shared heritage. Founded in 1793, The Society of Licensed Victuallers has a long and extensive charitable function, raising money both for members and for other charities (Elkins 1978). In fact, many of the existing licensed victuallers, and certainly a number of those we interviewed, had long- standing connections with DGV even before they moved there. Their shared occupational background also meant that they had been used to fund raising for the upkeep of DGV throughout their working lives and, once at DGV, the pub, club and shop proved to be the hub of community life. The traditional - or as one resident described it - 'the old time bar', was a popular venue for those with long-established links with the licensed trade:

I mean, when we first came here, if you weren't in the OwI Bar on a Wednesday evening, which was Licensees' night off, by eight o'clock you couldn't get in there, you couldn't get a seat. (Laurence Martin)

The pub not only provided a venue for shared interests but also symbolised the sense of continuity with residents' former working lives. Likewise, the concert-cum-dance hall was the location for regular village-wide entertainment. Other major events, such as the annual garden party at which residents and outsiders alike would mingle and socialise, were also vividly recalled by the licensed victuallers:

We used to have garden parties here ... huge garden parties and my husband used to do the catering. We had a hotel at the time in Wembley and we used to bring all the staff, the furniture here, everything here and it used to be 'best hat'. We used to 
do that every year in July ... everybody came ... and my sister-in-law and I always used to run a tombola. (Muriel Harris)

Shared leisure interests thus revolved primarily around the pub and the club but, at the same time, were oriented around fund-raising and other activities that bound the residents together as a community.

However, as the present-day village continues to expand, making a reality of what the promotional literature describes as 'a community of like-minded people' presents challenges where shared interests and leisure activities are concerned, not least because the occupational backgrounds of residents are becoming ever more diverse. From the late 1980s onwards, small numbers of non-licensed victuallers began to be admitted to DGV, but everyone still rented their properties. Under the redevelopment, Anchor Trust had to accommodate the existing residents and is contractually committed to admitting a fixed number of licensed victuallers each year into rented accommodation should they require places. However, with properties for sale now retailing at between $£ 250,000$ and $£ 500,000$, a more diverse and more mixed population of both leaseholders and tenants is being attracted to live at DGV.

Notwithstanding this increasing diversity, some of the longstanding licensed victuallers like Lillian Martin are still active in facilitating the more traditional kinds of activities in the new village: 'Oh yeah, I [play] Bingo on a Tuesday and I play whist on a Thursday and bowls on a Wednesday ... also we do run sometimes a tea dance you know, just now and again'. Others have worked hard at putting on events that might bring 'old' and 'new' residents together, including reviving the annual garden party. As the new village has developed and the population di- versified, so the nature of the organised activities on offer has expanded. Many residents feel that there is now considerable choice, both in terms of whether or not to participate and in terms of the opportunities to socialise and make friends. Pat Middleton, a widow who bought a house in 2006 , speaks for many when she writes:

There is so much to offer here that one need never be bored. I [take part in] the Film Club on Monday afternoons - exercise class is held on Tuesdays, Rummikub on Wednesday, Bridge on Thursday, Bowls, tea parties, a craft afternoon and coach outings are arranged to various places on occasion ... a Classical Music Appreciation class [is about to start] in our Activities Room. If residents have no wish to become involved then that is their choice, no one will force them into anything, but the options are there.

Choosing to attend social and leisure activities within the village is one way in which friendships can be formed with those who share similar interests, whether that be going for regular meals together in the cafe' bar, playing bowls or snooker, or going on the regular weekly shopping trips, as Violet Dixon describes: I go on the Friday coach yes ... and that's a social occasion too, isn't it, you can see ... people that you don't see otherwise'. Percy Kerr also tells us that a revived interest in table tennis is assisting friendship formation:

I have not played Table Tennis since I was at school 69 yrs ago but I decided to have a go, and found that I could still hit the ball most times!! Every week now I feel I am improving which is great because it combines useful exercise with an interesting challenge. It is a social game as usually the same people attend each week we are getting to know one another.

That said, diary entries, directives and our observations also show that informal social contacts - often in the communal places and spaces - are as important as they had been in the old village. Then, the layout of the bungalows, and the absence of fences, facilitated informal socialising amongst residents, especially in the summer months when, as Laurence Martin remarked: 'there would be a barbecue somewhere'. Today, residents tend to 
congregate just outside the shop while they wait for the bus or the regular Friday morning coach into Uxbridge, whilst the cafe' bar is a key facility for informal socialising. In addition, as Rose Cross observes: 'Many people know one another by sight or name and, if one walks through any of the communal areas, there is usually someone to have a chat to'. These two facets of community - both as 'interest' and as 'place' - in turn have implications for how community identity is forged and evolves over time. It is this aspect we now consider.

\section{DGV and 'community identity': then and now}

Feelings of belonging and attachment are at the heart of a shared sense of community identity and having a shared occupational background meant that, on arrival at DGV, many of the licensed victuallers felt a strong and almost immediate sense of connection both with the place and with other residents. As Laurence Martin said: 'we were all the same breed ... within a week you were part of the scene'. Having raised funds over the course of their working lives both for the development and the upkeep of the village, DGV very much belonged to the licensed victuallers and they to it. Indeed, a number of them continued to work at DGV, in either a paid or voluntary capacity, helping out in the kitchens or transporting residents round the site in the buggy. Nettie Gray told us:

First of all I was working in the kitchen with the catering company and then I went into the nursing home and did the bar. I was a month off 81 when I retired from there. I decided I would give it up. Most of it was voluntary. There was a time when ... I did get a small wage for doing the bar but really I was quite happy to do it.

If belonging, attachment and community identity was about participating in a collective enterprise and a shared lifestyle, it was also about the bonds between people and the friendships forged in this distinctive setting. Arthur Gibbs told us: 'the lady next door I am quite friendly with - known her for forty years', while Muriel Harris described friendship formation in these terms:

Being close and being connected with Denham, I always feel that ... [you] not only belonged to Denham ... you automatically ... all made lots of friends. The people that are here now who I knew years ago that still live here, we still keep together.

This sense of continuity with both people and place is important for maintaining continuity of the self. Even recent residents - without a lifetime's connection with DGV - spoke and wrote about how quickly they had settled in and felt 'at home', as Peter Groves explains:

We had had our previous house for a quarter of a century but when I am asked how long it took to feel at home in DGV, I generally pull a long face and answer 'about two hours'.

Some of these feelings of belonging and attachment also appear to be bound up with a sense of pride in the village and recognition of its distinctiveness and, even, exclusivity. George Hughes wrote that it felt like living in a 'first class hotel' whilst Millicent Cook told us:

The village appears to be a community and I feel proud to be part of it. My friends come to visit me and I feel happy to show them round the village. They are usually impressed.

Being part of the village is expressed in comments about its 'atmosphere' and 'feel' and in the accounts of neighbourliness and indications of friendship and support between residents. Further on in his diary George Hughes writes about the speed with which he and his wife have made friends, while other recent residents like Reg Jones told us that: 'For the first time in our lives we actually know our neighbours'. The support which exists is also encapsulated by Enid Foster when she writes: 'We all look out for each other and help where we can with shopping and giving each other a lift to hospital or to the shops'. 
However, lest it be assumed that this rosy portrait of DGV is one of unalloyed harmony, we turn now to consider the extent to which our findings also challenge and disconfirm some of the notions of community articulated above.

\section{Then and now, them and us: a community in transition?}

An evolving community such as DGV is not without its tensions and disagreements and the findings from our study reveal that even within this 'community of place' there are social divisions and evidence of social exclusion and social isolation. Recently arrived licensed victualler June Peters expresses this very directly when she writes:

I do not feel that there is a real community feel to the village at present. There is a lot of 'them and us' ie. original residents and new comers and also leaseholders and tenants ... there is a lot on offer. However, having said that, when you do attend you are not made particularly welcome if you are a new face. It is more like an individual existence rather than a village community. It is always up to you to make the first move, people don't seem to come to you.

For their part, some of the 'old' licensed victuallers like Arthur Gibbs and Rosa Scott also talk about this feeling of 'them and us'. Arthur says: 'Now, unfortunately, with the people that have bought here, there is a feeling of them and us'; while Rosa writes: 'New residents I feel resent we LVNH people, I don't know why, considering this was our land'.

That said, the picture is rather more complicated than simple divisions between the 'old' licensed victuallers and the newer people who have moved in since the redevelopment. Social divisions are rooted in a complex mixture of class, tenure, age, health status and size of the village, and may be expressed, for example, in participation or non-participation, engagement or non-engagement with what is happening. Newcomer Rebecca Jarvis writes that 'the large number of residents, rather than the difference of backgrounds, make it difficult to mix'; a point echoed by long-term resident Enid Foster: 'The size of the village makes it difficult to get to know all the people who live here where in the past we knew everyone'. Meanwhile, Rose Cross writes about how some of the other social divisions are reflected in the kinds of activities people do or do not take part in:

Some tenants did not welcome the leaseholders moving on site and that has been an issue right from the start. I think it's easier now but for a long time there was a problem ... it was very difficult for a while as there were awful barriers ... I think it's difficult to say people from differing backgrounds mix or don't mix well. What has happened is that leaseholders attend some activities whilst tenants go to others in the main. For example bingo attendees seem to be outsiders and tenants, whilst film club is always just leaseholders though naturally at a few events you get the mix.

However, not all 'new' residents are leaseholders and a number of the new people who rent, like Lilly Bradshaw, observed that the 'old' licensed victuallers were in fact less welcoming to new tenants than the new leaseholders were:

Well one of my main concerns when coming here was would there be a divide between rental and owners, as I would be renting ... I felt there might be a 'have and have not' feel. This was certainly not the case, I have made some good friends who share my own hobbies and thoughts on most things amongst the owners, who seemed if anything more friendly than the licensed trade retirees who seemed to have long lasting groups of friends ... and were not forthcoming in inviting you to join their groups. When I first went down to Bingo or Quiz night it was the owners who said 'Are you alone? Come and sit with us'.

Other residents make a conscious choice not to participate even though, like Arthur Gibbs, 
they may have been centrally involved in organising activities at one time:

I keep myself to myself pretty well. Suits me. I don't want to get involved. With all due respects I am old, they are all old people and their conversation can't be much.

Yet others are excluded from activities by virtue of their own tastes or because, try as they might, there is simply not the commitment or interest from other residents. Jerry Byrne spoke, for example, about how the shop no longer stocked his preferred newspaper, The Guardian, and how the Film Club shows 'old' films that do not interest him. Kathleen Lee meanwhile began by describing herself as "not really a "joiner"', then went on to tell us how she had tried to get a group of residents together to pursue a particular leisure activity:

We tried it for a few months, but there was not enough commitment to be able to keep it going - this was disappointing as both she and I had put a lot of effort in this to make it work.

For others like Nettie Gray and Vera Poole, health status and mobility issues, coupled with the location of their accommodation, present barriers to participation and to their ability to form and maintain relationships:

The bungalow I felt had a lovely veranda and I could sit out there even if, you know, it was covered in and I could see people. But here, I'm looking over onto just those houses. I mean I am quite happy. It is only that as you get older and you can't get out at all, it could be very grim, not being able to see people walk past. (Nettie Gray)

Unfortunately I have become less mobile and not able to walk far since moving here, so I am unable to join in any activity unless I pay for a carer to take me in a wheelchair ... I do not know any other residents because I cannot go out for a walk. Sometimes I do not see or speak to anybody for a week. (Vera Poole)

Some people are also excluded from activities because other residents and/or staff consider that they are unable to participate because of their health status. This applies particularly to people with conditions such as dementia which, although not overtly raised by residents, was highlighted by some of our key informants:

We talked at one stage about having a bit of a dementia wing ... to help people who are coming into the community and needing some support, but who weren't, presumably, totally dependent ... one of the things which is important for dementia is an environment which they can easily, sort of, find their way around ... I think it would be very confusing for them ... there are bits of the scheme that probably wouldn't be very suitable, with all honesty. (Key 11)

I guess it's once you start to get to dementia and people's ability to cope for themselves ... once you get to that level of frailty, that's when you start to question actually whether this environment would suit those type of individuals. (Key 9)

There is an additional issue about the community outside the physical boundaries of the village and the fact that a number of the leisure facilities (the gym, cafe' bar etc.) and the GP surgery are open to external visitors. Even when only licensed victuallers lived at DGV, the pub and other facilities were technically 'open' but, in reality, some key informants felt that, as far as the outside community was concerned, DGV was 'Completely isolated ... the LVNH ran it as a little island really and the fact that it was in Denham was just coincidental, it could've been anywhere ... the only thing that was integrated was the pub ' (Key 6). Under the redevelopment, Anchor Trust 'took some decisions, very early on, that the communal facilities ... would be open to the wider community ... that we wouldn't restrict it simply to the older people, living there' (Key 1). This was a decision taken both on commercial grounds 
and as matter of principle, but one which has prompted conflicting responses.

From the perspective of one key informant, this decision has been a beneficial one:

I think there has been a nice integration with the local community ... you'll go into the gymnasium, or you'll go into the swimming pool, and you'll see young people with children, or you'll see, kind of, 25 year olds, on jogging machines, next to older people ... I think it was good to put a GP practice on the site, I think that has worked well because, again, that's brought the local community in and made it feel more integrated. (Key 1)

However, for those who live there, the 'public', 'visitors', or 'outsiders' - as they are variously termed - are clearly identified as not being part of the village community and this manifests itself in, for example, disputes about the limited parking in the village centre and around the surgery. Another key informant summed these tensions up in these terms:

Do you interact with people you see at your GP surgery? ... it'll bring them [the outside community] in, and then they'll go out again ... just putting a gym in - it's the same as the GP, isn't it - people come into the gym, and they go out again. And they might stop and get a cup of coffee on the way, but that doesn't mean they're going to have any involvement, or any interaction, with the people that live there. (Key 3)

Not surprisingly then, the community dynamics within the village are complex and changing; relationships are forming and evolving, as are feelings of attachment and belonging. The introduction of 'outsiders' and 'new' people into an already existing community - albeit one that has undergone a major physical redevelopment - challenges and disturbs longestablished bonds and ways of being and relating to one another. For some, this means that DGV "has lost that "togetherness"' (Freda Parker) whilst, for others, change is embraced and welcomed. As Phyllis Horton put it: 'I think the village will mature and evolve as time goes by' while one of the key informants observed that: 'I suppose in a sense you can't create communities really, but you can put in place structures that may encourage that' (Key 11).

\section{DISCUSSION: A RETIREMENT COMMUNITY FOR THE $21^{\text {ST }}$ CENTURY}

Retirement communities like DGV are boundaried physical places and spaces within which issues around environment, identity and age collide. These in turn find expression in differing conceptualisations and understandings of community. In the case of DGV, time and change over time - is key to this dynamic. Our findings illustrate not only the complexity of articulating 'community', but also the dynamic and evolving nature of those meanings over time. In discussing these aspects further, we first revisit the three-fold classification of community into 'place', 'interest' and 'identity' and consider some of the implications for our understandings of what 'community' is about in the context of a 21 st-century, purpose-built retirement village.

Our findings indicate that the original licensed victuallers identified psychologically and emotionally with DGV as a place throughout their lives and, when they moved into the village, they brought with them a strong sense of ownership and community. For those who chose to stay, DGV as a place reflected their sense of identity as licensed victuallers and provided a setting in which to pursue shared leisure activities. Even the arrival of nonlicensed victuallers from the late 1980s onwards did not seem to disturb this perhaps rather traditional, rose-tinted 'sense of community' and these incomers appear to have been successfully assimilated into life at DGV. Today, there is still strong evidence that 'community of place' retains a salience and meaning for residents both 'old' and 'new'. The shared physical location, its identifiable boundaries, and the importance of centrally located communal facilities like the café bar and surgery are all consistent with the literature and 
empirical research on what makes for a geographically distinctive community (Andrews and Phillips 2005; Croucher, Hicks and Jackson 2006; Peace, Holland and Kellaher 2006; Rowles 1978; Smith 2009).

The built environment also impacts on residents' sense of community, both positively in terms of spaces and places that facilitate social interaction (Evans and Means 2007), and negatively in the instances where people felt geographically distant and socially isolated (Evans 2009 b). Residents with mobility, health or financial difficulties can find themselves limited in the extent to which they are able to participate in village life or socially interact with other residents. By contrast, others see the village as a friendly and supportive place in which they have been able to form friendships with other residents, supporting the findings of several recent studies of such environments (Bernard et al. 2004; Croucher, Pleace and Bevan 2003; Evans and Means 2007). Often too, these friendships have developed through shared interests and activities, whilst 'neighbourly' and supportive behaviours were also identified as important. Thus, despite the literature suggesting that 'communities of interest' are increasingly transcending geographical boundaries (Evans 2009a; Massey 2005; Savage 2008), we would contend that DGV is a clear example of where communities of place and interest still coincide.

However, these two facets of community do not automatically translate into a shared sense of identity. Whilst the licensed victuallers appear to retain the kinds of bonds and patterns of shared meaning described by Crow and Allan (1994), the population of DGV is now larger and more socially and economically, if not ethnically, diverse. There is a sense that the 'old' licensed victuallers are increasingly 'a community within a community', the bonds between them having been reinforced by the arrival of 'new' residents (Crow and Allan 1994) and expressed in some of the social divisions between them and newer residents. They feel DGV has lost its sense of 'togetherness', in contrast to those who are conscious that the village is in a period of transition. A sense of shared identity is still evolving and, as might be expected from the literature (Croucher, Hicks and Jackson 2006; Crow and Allan 1994), this leads to tensions and differing perceptions of what the community is like and, on occasion, to negative perceptions of ageing and intimations of ageism between residents.

As we have seen, 'new' residents sometimes found it difficult to 'join in' with certain activities whilst some of the 'old' licensed victuallers felt that 'new' residents resented them and did not appreciate the history, heritage and hard work of those who had developed and kept the village running for more than 40 years before Anchor Trust took it over. At the time of writing, the physical redevelopment has only just been completed and, as yet, the village is not up to full capacity in terms of the numbers of residents it will eventually accommodate. In some ways then, it is not surprising that the village is not entirely socially cohesive if, indeed, this is ever possible. However, for one key informant, DGV will only have succeeded in becoming a true 21st-century community if:

At some point you reach a stage where this is just another part of the local community: it's another set of roads, another set of houses, that are part of the local community, and it happens to have these great facilities in there so people, sort of, come and go, because it is part of the community ... but, if you don't start off by making those positive links - with schools and things like that - then it's not going to happen by accident. (Key 3)

\section{CONCLUSION}

Our findings show that, even within the physical confines of a purpose- built retirement village, the ideal of a completely cohesive community is just that: an ideal. A homogeneous community where there is complete consensus is unrealistic, and in any case would in all likelihood be oppressive, conformist and intolerant of differences. It is also a moot point whether, in the future, DGV will ever approximate to the idealised image of rural village life. 
A number of those we interviewed confirmed that they felt the village was 'transitional' and hoped that it would 'sort of settle down' (Key 2) over the next five years or so. Others felt that both residents and staff needed to be more proactive in forging links within and beyond the physical confines of DGV if they are to make a reality of it as a new, vibrant and integrated community.

Studying retirement villages through the theoretical lens of 'community' - in this instance in its different dimensions of place, interest and identity - has offered us one way of understanding both the dynamics of change over time, and the active engagement of older people in making and re-making meaning in a very particular environment: one which has physically removed them from the wider institutions of everyday life. A mixed-method study of this nature, carried out over a four-year period and which has looked at the development of one particular retirement village both retrospectively and prospectively, also provides insights into how residents and others perceive and understand their day-to-day experiences of living and working in such an environment. It seems as if residents simultaneously conceive of DGV as a boundaried physical place as well as a community - or indeed an interlocking set of communities - which retains biographical and symbolic importance for some individuals. For others, DGV as a 'community in place' (Evans 2009a: 129) is in itself constraining, particularly at a time when 'place' is less salient to how community is understood and experienced by the wider population. Future research on retirement villages might usefully develop some of these findings. This would enable us not only to contribute further to empirically grounded theories of social change, but would also add to the growing critique around such age-segregated developments as our societies continue to grapple with ways to respond to the ageing of the population.

\section{ACKNOWLEDGEMENTS}

This research was financially supported by Anchor Trust and we would like to acknowledge their co-operation and that of the residents and staff at Denham Garden Village. Our appreciation also goes to Dr Allison Smith and Dr Jenny Hislop, both former members of the LARC research team, and to the two anonymous reviewers who commented on an earlier draft of this paper.

\section{NOTES}

${ }^{1}$ A series of technical reports on the LARC website provide detailed information about recruitment and data collection methods (see www.keele.ac.uk/larc/ downloads).

${ }^{2}$ For reasons of anonymity, no further details about these respondents are provided in this article.

\section{REFERENCES}

Andrews, G. J. and Phillips, D. R. 2005. Ageing and Place: Perspectives, Policy and Practice. Routledge, Abingdon, UK.

Bernard, M., Bartlam, B., Biggs, S. and Sim, J. 2004. New Lifestyles in Old Age: Health, Identity and Well-being in Berryhill Retirement Village. The Policy Press, Bristol, UK.

Bernard, M., Bartlam, B., Sim, J. and Biggs, S. 2007. Housing and care for older people: life in an English purpose-built retirement village. Ageing \& Society, 27, 4, 555-78.

Bernard, M. and Scharf, T. (eds) 2007. Critical Perspectives on Ageing Societies. The Policy Press, Bristol, UK.

Bibby, P. and Shepherd, J. 2004. Developing a New Classification of Urban and Rural Areas for Policy Purposes - The Methodology. Available online at 
http://www.statistics.gov.uk/geography/downloads/Methodology_Report.pdf [Accessed May 2010].

Biggs, S., Bernard, M., Kingston, P. and Nettleton, H. 2000. Lifestyles of belief: narrative and culture in a retirement community. Ageing \& Society, 20, 6, 649-72.

Blakely, E. J. and Snyder, M. G. 1999. Fortress America: Gated Communities in the United States. Brookings Institution Press, Washington DC.

British Standards Institute 2007. Design of Accessible Housing: Lifetime Home. Code of Practice. DD 266, British Standards Institute, London.

Burgess, E. W. 1961. Retirement Villages. University of Michigan, Ann Arbour, Michigan.

Burholt, V. 2006. 'Adref' : theoretical contexts of attachment to place for mature and older people in rural North Wales. Environment and Planning A, 38, 6, 1095-114.

Canter, D. 1977. The Psychology of Place. Architectural Press, London.

Croucher, K., Hicks, L., Bevan, M. and Sanderson, D. 2007. Comparative Evaluation of Models of Housing with Care for Later Life. Joseph Rowntree Foundation, York, UK.

Croucher, K., Hicks, L. and Jackson, K. 2006. Housing with Care for Later Life. Joseph Rowntree Foundation, York, UK.

Croucher, K., Pleace, N. and Bevan, M. 2003. Living at Hartrigg Oaks : Residents' Views on the UK's First Continuing Care Retirement Community. Joseph Rowntree Foundation, York, UK.

Crow, G. and Allan, G. 1994. Community Life: An Introduction to Local Social Relations. Harvester Wheatsheaf, Hemel Hempstead, UK.

Denham Garden Village 2009. Homepage. Available online at http://www.anchor.org. uk/PropertiesAndCareHomes/PropertiesForSale/DenhamGardenRetirementVillage/ default [Accessed August 2009].

Department for Communities and Local Government 2008. Lifetime Homes, Lifetime Neighbourhoods: A National Strategy for Housing in an Ageing Society. Department for Communities and Local Government, London.

Eade, J. (ed.) 1997. Living the Global City: Globalization as a Local Process. Routledge, London.

Easthope, H. 2004. A place called home. Housing, Theory and Society, 21, 3, 128-38.

Elderly Accommodation Counsel 2009. Directory of Retirement Villages and Communities in the UK. Available online at http://www.housingcare.org/elderly-uk-retirement-villages. aspx [Accessed May 2010].

Elkins, T. 1978. Our Trade. Showerings Ltd, Shepton Mallet, UK.

Evans, S. 2009 a. Community and Ageing: Maintaining Quality of Life in Housing with Care Settings. The Policy Press, Bristol, UK.

Evans, S. 2009b. 'That lot up there and us down here': social interaction and a sense of community in a mixed tenure UK retirement village. Ageing \& Society, 29, 2, 199-216.

Evans, S. and Means, R. 2007. Balanced Communities? A Case Study of Westbury Fields Retirement Village. St Monica Trust, Bristol, UK. 
Holloway, L. and Hubbard, P. 2001. People and Place: The Extraordinary Geographies of Everyday Life. Pearson, Harlow, UK.

Jacobs, J. 1983. Fun City: An Ethnographic Study of a Retirement Community. Waveland Press, Prospect Heights, Illinois.

Jones, A., Howe, A., Tilse, C., Bartlett, H. and Stimson, B. 2009. Service Integrated Housing for Australians in Later Life. Final Report No. 141, Australian Housing and Urban Research Institute, Melbourne.

Karn, V. 1977. Retiring to the Seaside. Routledge and Kegan Paul, London.

Katz, S. and McHugh, K. 2010. Age, meaning and place: cultural narratives and retirement communities. In Cole, T. R., Ray, R. E. and Kastenbaum, R. (eds), A Guide to Humanistic Studies in Aging. Johns Hopkins University Press, Baltimore, Maryland, 271-92.

Laws, G. 1995. Embodiment and emplacement: identities, representation and landscape in Sun City retirement communities. International Journal of Aging and Human Development, $40,4,253-80$.

Laws, G. 1997. Spatiality and age relations. In Jamieson, A., Harper, S. and Victor, C. (eds), Critical Approaches to Ageing and Later Life. Open University Press, Milton Keynes, UK, 90-100.

Marans, R. W., Hunt, M. E. and Vakalo, K. L. 1984. Retirement communities. In Altman, I., Lawton, M. P. and Wohlwill, J. F. (eds), Elderly People and the Environment. Plenum, New York, 57-93.

Mason, J. 2006. Real life methods working papers: six strategies for mixing methods and linking data in social science research. Manchester University, Manchester, UK.

Massey, D. 2005. For Space. Sage, London.

McHugh, K. 2000. The 'ageless self'? Emplacement of identities in Sun Belt retirement communities. Journal of Aging Studies, 14, 1, 103-15.

McMillan, D. W. 1996. Sense of community. Journal of Community Psychology, 24, 4, 31525.

McMillan, D. W. and Chavis, D. M. 1986. Sense of community: a definition and theory. American Journal of Community Psychology, 14, 1, 6-23.

Nelson, T. D. 2005. Ageism: prejudice against our feared future self. Journal of Social Issues, 61, 2, 207-22.

Osgood, N. J. 1982. Senior Settlers: Social Integration in Retirement Communities. Praeger, New York.

Peace, S., Holland, C. and Kellaher, L. 2005. The influence of neighbourhood and community on well-being and identity in later life: an English perspective. In Rowles, G. D. and Chaudhury, H. (eds), Home and Identity in Late Life: International Perspectives. Springer, New York, 297-316.

Peace, S., Holland, C. and Kellaher, L. 2006. Environment and Identity in Later Life. Open University Press, Buckingham, UK.

Peace, S., Wahl, H. W., Mollenkopf, H. and Oswald, F. 2007. Environment and ageing. In 
Bond, J., Peace, S., Dittman-Kohli, F. and Westerhof, G. (eds), Ageing in Society: European Perspectives on Gerontology. Sage, London, 209-34.

Phillipson, C. and Allan, G. A. 2008. Community studies today: urban perspectives. International Journal of Social Research Methodology: Theory \& Practice, 11, 2, 163-73.

Plas, J. M. and Lewis, S. E. 1996. Environmental factors and sense of community in a planned town. American Journal of Community Psychology, 24, 1, 109-43.

Ritchie, J., Spencer, L. and O'Connor, W. 2003. Carrying out qualitative analysis. In Ritchie, J. and Lewis, J. (eds), Qualitative Research Practice: A Guide for Social Science Students and Researchers. Sage, London, 219-62.

Rose, G. 1995. Place and identity: a sense of place. In Massey, D. and Jess, P. (eds), A Place in the World?: Places, Cultures and Globalization. Oxford University Press, Oxford, 87-132.

Ross, J. K. 1977. Old People, New Lives: Community Creation in a Retirement Residence. University of Chicago Press, Chicago.

Rowles, G. D. 1978. Prisoners of Space?: Exploring the Geographical Experience of Older People. Westview Press, Boulder, Colorado.

Rowles, G. D. and Watkins, J. F. 2003. History, habit, heart and hearth: on making spaces into places. In Schaie, H. W., Wahl, H. W., Mollenkopf, H. and Oswald, F. (eds), Aging Independently: Living Arrangements and Mobility. Springer, New York, 77-96.

Sarason, S. B. 1974. The Psychological Sense of Community: Prospects for a Community Psychology. Jossey-Bass, San Francisco.

Savage, M. 2008. Histories, belongings, communities. International Journal of Social Research Methodology, 11, 2, 151-62.

Savage, M., Bagnall, G. and Longhurst, B. J. 2005. Globalisation and Belonging. Sage, London.

Scharf, T., Phillipson, C. and Smith, A. 2007. Aging in a difficult place: assessing the impact of urban deprivation on older people. In Wahl, H. W., Tesch-Romer, C. and Hoff, A. (eds), New Dynamics in Old Age: Individual, Environmental, and Societal Perspectives. Baywood, Amityville, New York, 153-74.

Simpson, M. 2007. Organisational transformations in the New Zealand retirement village sector: a critical-rhetorical and -discursive analysis of promotion, community, and resident participation. Unpublished PhD thesis, University of Waikato, Hamilton, New Zealand.

Smith, A. E. 2009. Ageing in Urban Neighbourhoods: Place Attachment and Social Exclusion. Policy Press, Bristol, UK.

Streib, G. F. 2002. An introduction to retirement communities. Research on Aging, 24, 1, 3-9.

Streib, G. F. and Metsch, L. R. 2002. Conflict in retirement communities: applying an analytical framework. Research on Aging, 24, 1, 67-86.

Sugihara, S. and Evans, G. W. 2000. Place attachment and social support at continuing 
care retirement communities. Environment and Behaviour, 32, 3, 400-9.

Tuan, Y. F. 1977. Space and Place. Arnold, London.

Tuan, Y. F. 2001. Space and Place: The Perspective of Experience. University of Minnesota Press, Minneapolis, Minnesota.

van den Hoonaard, D. K. 2002. Life on the margins of a Florida retirement community: the experience of snowbirds, newcomers, and widowed persons. Research on Aging, 24, 1, $50-66$.

Webster, C. 2002. Property rights and the public realm: gates, green belts, and Gemeinschaft. Environment and Planning B, 29, 3, 397-412. 